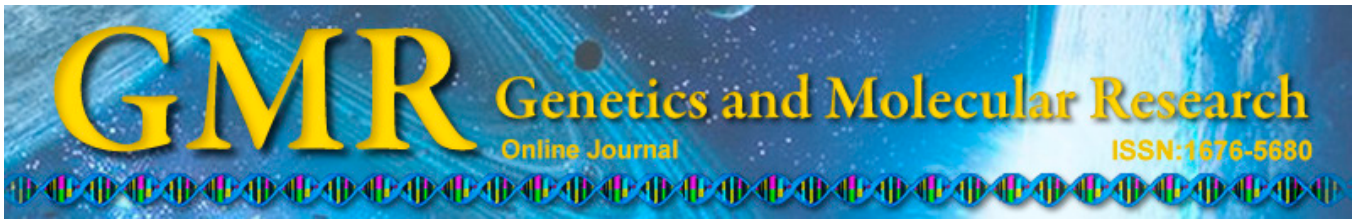

\title{
Effect of skeletal muscle fibers on porcine meat quality at different stages of growth
}

\author{
F. Wu ${ }^{1,2,3}$, J.J. Zuo ${ }^{1,2,3}$, Q.P. Yu', S.G. Zou ${ }^{3,4}$, H.Z. Tan ${ }^{3,4}$, J. Xiao ${ }^{1}$, \\ Y.H. Liu ${ }^{1}$ and D.Y. Feng ${ }^{1,2,3}$ \\ ${ }^{1}$ College of Animal Science, South China Agricultural University, Guangzhou, \\ Guangdong, China \\ ${ }^{2}$ South China Observatory, \\ Agriculture Ministry Key Laboratory of Animal Nutrition and Feed Science, \\ Guangzhou, Guangdong, China \\ ${ }^{3}$ National Engineering Research Center for Breeding Swine Industry, \\ Guangzhou, Guangdong, China \\ ${ }^{4}$ Production Technology Department of WENs Group, Xinxing, \\ Guangdong, China \\ Corresponding author: J.J. Zuo \\ E-mail: zuojj2000@163.com
}

Genet. Mol. Res. 14 (3): 7873-7882 (2015)

Received November 12, 2014

Accepted April 24, 2015

Published July 14, 2015

DOI http://dx.doi.org/10.4238/2015.July.14.13

\begin{abstract}
In this study, we examined changes in meat quality and content of muscle types during porcine growth. The influence of the longissimus dorsi muscle fiber composition on meat quality and the correlation between 2 fiber-typing methods (histochemistry and realtime quantitative polymerase chain reaction) were examined. Type IIx and type IIb fibers accounted for most of the total number of fibers; the proportion of these fibers increased during porcine growth (75.42, 80.09 , and $79.88 \%$, respectively, at 3 different stages of growth). There was a strong positive correlation between the 2 fiber-typing methods; the correlation coefficients of type I, IIa, and IIx+IIb fiber contents were $0.65,0.88$, and 0.92 , respectively. The $a^{*}$ value of meat color was significantly lower at 98 days and negatively correlated with white fiber
\end{abstract}


content $(\mathrm{r}=-0.69, \mathrm{P}<0.01)$. Water-holding capacity decreased during porcine growth. The drip loss parameter was positively correlated with type IIx+IIb fiber content $(\mathrm{r}=0.55, \mathrm{P}<0.05)$. Decreased $\mathrm{pH}$ was strongly positively correlated with type IIx + IIb fiber content $(\mathrm{r}=0.61$, $\mathrm{P}<0.01)$ and negatively correlated with type IIa fiber content $(\mathrm{r}=-0.44$, $\mathrm{P}<0.05)$. Therefore, we found that the composition of muscle fibers influenced the establishment of meat quality and its alteration during the early postmortem period.

Key words: Drip loss; Longissimus dorsi; Meat color; Muscle fiber type; Real-time quantitative polymerase chain reaction

\section{INTRODUCTION}

With improvements in the quality of life, meat quality has gained increased attention. To produce high-quality meat, it is important to understand meat quality traits and their regulation. Meat color, water-holding capacity, and $\mathrm{pH}$ are important traitsused as indicators of freshness and juiciness (Joo et al., 2013). Meat quality is affected by muscle fiber characteristics and other factorssuch asmuscle structure, chemical composition, and postmortem changes in the conversion of muscle to meat (Jiang et al., 2004; Joo et al., 2013; Ye et al., 2013).

Vertebrate skeletal muscles consist of muscle fiber, connective tissue, intramuscular fat, vesicular tissue, and neural tissue (Plomgaard et al., 2006). Muscle fiber amajor component of muscle, it is an important factor determining meat quality (Joo et al., 2013). Based on morphological traits and structural, contractile, and metabolic properties, porcine muscle fibers are classified into 4 types: slow-twitch oxidative fiber type I, fast-twitch oxidative fiber type IIa, fast-twitch oxido-glycolytic fiber type IIx, and fast-twitch glycolytic fiber typeIIb (Schiaffino and Reggiani, 1994; Wimmers et al., 2008; Lee at al., 2010). Other methods have been used to classify muscle fibers. Brooke and Kaiser (1970) classified muscle fibers into types I,IIa, and IIb based ontheir ATPase activities. Brooke and Kaiser (1970), Baker and Santer (1990), and Larzul et al. (1997) classified muscle fibers into 4 types (I, IIa, IIbr, and IIbw) based on the acid stability of the myosin ATPase reaction and succinate dehydrogenase staining.

However, traditional muscle fiber typing methods have yielded inconsistent results. Therefore, new methods including immunohistochemical and genomic techniques have been used to classify fibers (Lin et al., 2002; Yang et al., 2014). However, the relationships among different methods remain unclear. To examine the correlation between different methods, we classified fibers using immunohistochemistry and real-time quantitative polymerase chain reaction (qPCR).

Muscle fiber composition affects skeletal muscle structure, biochemical properties, and function, which directly impact meat quality traits (Karlsson et al., 2000). Meat color, pH, water-holding capacity, and intramuscular fat are important quality traits from the consumer's perspective (Takawa et al., 2012). Fiber composition is considered to affect meat quality traits; however, the relationships between fiber type and specific meat quality parameters remain unclear. In this study, we examined these relationships to establish a theoretical basis for controlling meat quality through fiber-type transformation. 


\section{MATERIAL AND METHODS}

\section{Animal and muscle sampling}

Sixty castrated hybrid male pigs (Landrace $\mathrm{x}$ Large White $\mathrm{x}$ Duroc) were used in this study. The average weight of the pigs at the beginning of the experiment was $7.27 \pm 0.13 \mathrm{~kg}$. The animals were divided into 6 stalls with 10 pigs in each stall. All animals were housed in a controlled environment and provided free access to food and water. The animals were reared in strict compliance with the Chinese regulations for the care and use of animals in research. The experimental diet was designed according to the NRC2012 (nutrient requirements of swine, 11th revised edition, 2012) as follows: $10-30 \mathrm{~kg}$ stage: $19.2 \%$ cude protein (CP), $1.02 \%$ available lysine, and $3300 \mathrm{kcal}$ digestive energy (DE) $/ \mathrm{kg} ; 30-60 \mathrm{~kg}$ stage: $17.2 \% \mathrm{CP}$, $0.85 \%$ available lysine, and $3300 \mathrm{kcal} \mathrm{DE} / \mathrm{kg} ; 60-110 \mathrm{~kg}$ stage: $15.2 \% \mathrm{CP}, 0.69 \%$ available lysine, and $3300 \mathrm{kcal} \mathrm{DE} / \mathrm{kg}$ ). The experiment began when the pigs were 35 days old, followed by a 5 -day period to adapt the new diet.

We slaughtered 6 pigs at 63, 98, and 161 days of age, 1 from each stall. During the night before slaughter, the pigs were allowed ad libitum access to water but not food. The following morning, the pigs were slaughtered by electrical stunning and exsanguinations (Lefaucheur et al., 2004). The longissimus dorsi muscle was isolated as a representative sample. Within $1 \mathrm{~h}$ after slaughter, muscle samples were taken, mounted on tongue depressors, placed in freezing tubes, and stored in liquid nitrogen before transfer to a $-80^{\circ} \mathrm{C}$ freezer.

\section{Physicochemical analyses}

Forty-five minutes and $24 \mathrm{~h}$ after slaughter, three $12 \times 12$ × $5 \mathrm{~cm}$ samples of the longissimus muscle at the last rib level were obtained to determine the color (Opto-star color analyzer, Matthaus, Germany), marbling, and pH of skeletal muscle (DELTA $320 \mathrm{pH}$ meter; Mettler Toledo, Greifensee, Switzerland). Marbling scores were determined by the marbling standards of the National Pork Producers Council, and the average value of 10 judges' marks was recorded. Five $\mathrm{pH}$ measurements were performed for each sample ( 5 small incisions were made in the meat and the $\mathrm{pH}$ meter probe was placed into the incisions to test muscle $\mathrm{pH}$ ), and the average value was recorded as the sample $\mathrm{pH}$ (Norman et al., 2004).

\section{Water holding capacity}

Within $2 \mathrm{~h}$ after slaughter, a sample of longissimus muscle $(4 \times 4 \times 2 \mathrm{~cm})$ at the last 3-4 thoracic vertebra level was excised, hanged using a hook in a plastic bag, and stored at $4^{\circ} \mathrm{C}$. The percentage of weight change after $48 \mathrm{~h}$ hanging was calculated as the drip loss of skeletal muscle (Schäfer et al., 2002).

\section{Histological analyses}

Transverse serial sections of all muscle samples were generated using a cryostat (Leica Microsystems Nussloch GmbH, Leica CM 1850, made in Germany; set at $10 \mu \mathrm{m}$ ) at $-20^{\circ} \mathrm{C}$ (Larzul et al., 1997). We integrated myosin ATPase histochemistry with succinate dehydrogenase histochemistry as follows. The sections were stained for 45 min using succinate 
dehydrogenase after pre-incubation at $\mathrm{pH} 4.35$ (Lefaucheur et al., 2002). The sections were thenwashed and stained for $30 \mathrm{~min}$ by using myosin ATPase (Nachlas et al., 1957). Images of all sections were captured using a CCD camera connected to an optical microscope, and image analysis software was used to determine the fiber type. The fibers were classified into MyHC types I, IIa, and IIx+IIb. We prepared 5 sections for each pig and chose 3 microscope fields for counting and calculation. All photos were taken at 100X magnification.

\section{Total RNA extraction and reverse transcription}

Total RNA was isolated from all muscle samples using TRIzol reagent (Life Technologies, Los Angeles, CA, USA), according to manufacturer instructions. The RNA samples were treated with DNase to eliminate trace genomic DNA contamination. Total RNA was quantified by measuring the absorbance at $260 \mathrm{~nm}$. The 260/280 and 260/230 $\mathrm{nm}$ absorbance ratios were measured to determine the purity of the isolated RNA. The integrity of the extracted RNA was determined by examining the $28 \mathrm{~S}$ and $18 \mathrm{~S}$ rRNA bands on ethidium bromide-stained agarose gels (Wimmers et al., 2008). Using total RNA as a template and oligo dT18 as a primer, reverse transcription reactions were performed to generate cDNA using reverse transcriptase and an RNase inhibitor. The cDNAs of the muscle samples were stored at $-80^{\circ} \mathrm{C}$ until use.

\section{qPCR}

The Oligo 7 (www.oligo.net) and Primer Premier 5 software (Premier Biosoft, Palo Alto, $\mathrm{CA}, \mathrm{USA}$ ) were used to design primers to amplify the MyHC isoform genes and a housekeeping gene for qPCR. Because the MyHC isoform genes belong to a single family, their sequences are highly similar. To amplify specific PCR products, we compared the gene sequences and designed primers annealing to regions with low similarity (Lefaucheur et al., 2004). The primer sequences and PCR conditions used are listed in Table 1. The quantitative reverse transcription-PCR were performed on an ABI 7500 machine (Applied Biosystems, Foster City, CA, USA) using the cDNA as template and the SYBR Green fluorescent dye (Life Technologies, Carlsbad, CA, USA). The thermal cycling parameters were as follows: an initial denaturation step at $95^{\circ} \mathrm{C}$ for $10 \mathrm{~min}$, followed by 40 cycles of denaturation at $95^{\circ} \mathrm{C}$ for $15 \mathrm{~s}$ and annealing and extension at $60^{\circ} \mathrm{C}$ for $1 \mathrm{~min}$. The expression of different MyHC mRNAs were determined as $2^{-\Delta \Delta \mathrm{Ct}}$, where $\Delta \mathrm{Ct}$ was the difference in $\mathrm{Ct}$ between the $\mathrm{MyHC}$ and glyceraldehyde 3-phosphate dehydrogenase. The relative amounts of MyHCI, IIa, IIx, and IIb were expressed as the percentage of total MyHC transcripts (Lefaucheur et al., 2002; Bustin et al., 2009).

\begin{tabular}{|c|c|c|c|}
\hline GenBank accession No. & Gene & Primer sequence (5'-3') & Annealing temperature $\left({ }^{\circ} \mathrm{C}\right)$ \\
\hline NM_001206359.1 & GAPDH & F: TGATTCCACCCACGGCAAG & 59 \\
\hline NM_213855.1 & MyHCI & $\begin{array}{l}\text { F: CCAGATCATCCAGGCCAACCC } \\
\text { R: CAGACGCCAACTTTCCAGTCG }\end{array}$ & 60 \\
\hline NM_214136.1 & MyHCIIa & $\begin{array}{l}\text { F: ATTCTCCAGGAAGCTCGCAAC } \\
\text { R: ATTCTCCAGGAAGCTCGCAAC }\end{array}$ & 59 \\
\hline NM_001104951.1 & MyHCIIx & $\begin{array}{l}\text { F: CCAGATCATCCAGGCCAACCC } \\
\text { R: CAGACGCCAACTTTCCAGTCG }\end{array}$ & 60 \\
\hline NM_001123141.1 & MyHCIIb & $\begin{array}{l}\text { F: CAAGTTGGCACAAGAATCCACA } \\
\text { R: TCCTCCAGCTCCTCAGTACGG }\end{array}$ & 59 \\
\hline
\end{tabular}




\section{Statistical analysis}

The data were analyzed using the SAS 9.0 package (SAS Institute Inc., Cary, NC, USA). The MIXED procedure was used to analyzemeat quality traits. The results are reported as the least square means with standard errors. Differences between the measured quantities were analyzed using the $t$-test; $\mathrm{P}<0.05$ was considered to represent a significant difference. Pearson's correlation coefficients were determined using partial correlation coefficients to analyze the correlation between meat quality traits and muscle fiber composition (Scott et al., 2001).

\section{RESULTS}

\section{Content of different muscle fiber types}

Muscle fibers were classified into 3 types (I, IIa, and IIx+IIb) based on the acid stability of myosin ATPase and the glycolytic rate (Table 2 and Figure 1). The MyHCIIx+IIb fiber constituted the highest percentage of the total number of fibers at all 3 stages $(75.42,80.09$, and $79.88 \%$ at 63,98 , and 161 days, respectively). In general, fast-growing pigs showed a higher percentage of glycolytic fibers. The percentage of fiber I was significantly lower at 63 days $(3.12 \pm 0.40 \%)$ than at 98 and 161 days $(\mathrm{P}<0.05)$. Unlike fiber I, the content of the other red fiber II as howed a downward trend in the 3 stages tested. The percentage of fiber IIa was significantly higher at 63 days than that at 98 and 161 days $(\mathrm{P}<0.05)$. The percentage of red fibers (I and IIa) followed a downward trend similar to that observed with fiber IIa. Furthermore, there was an increasing trend in the content of fiber IIx+IIb. The percentages of fiber IIx+IIb were significantly higher at 98 and 161 days than at 63 days $(\mathrm{P}<0.05)$, but not significantly different from each other $(\mathrm{P}>0.05)$.

Table 2. Percentages of different muscle fibers in the longissimus dorsi muscle at different stages of porcine growth.

\begin{tabular}{lccc}
\hline Muscle fiber type (\%) & \multicolumn{1}{c}{63 days } & 98 days & 161 days \\
\hline MyHC I & $3.12 \pm 0.40^{\mathrm{a}}$ & $6.98 \pm 0.78^{\mathrm{b}}$ & $7.65 \pm 0.97^{\mathrm{b}}$ \\
MyHCIIa & $21.47 \pm 0.99^{\mathrm{b}}$ & $12.94 \pm 1.65^{\mathrm{a}}$ & $12.47 \pm 1.16^{\mathrm{a}}$ \\
MyHCIIx+IIb & $75.42 \pm 1.29^{\mathrm{a}}$ & $80.09 \pm 1.50^{\mathrm{b}}$ & $79.88 \pm 1.64^{\mathrm{b}}$ \\
MyHCI+IIa & $24.59 \pm 1.29^{\mathrm{b}}$ & $19.91 \pm 1.28^{\mathrm{a}}$ & $20.12 \pm 1.09^{\mathrm{a}}$ \\
\hline
\end{tabular}

Data with different superscripts in the same row are significantly different $(\mathrm{P}<0.05)$. Percentage of red fibers was significantly higher at 63 days than at 98 and 161 days.

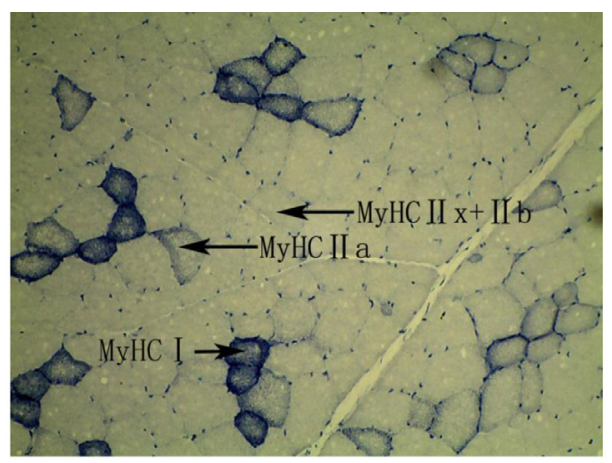

Figure 1. Type I fiber is stained dark blue; the type IIx+IIb fiber was unstained; type IIa fiber is shown in gray. Three fields of microscope for each section were counted and muscle fiber percentages were calculated. 


\section{Expression of MyHC genes at different stages of growth}

The percentages of different fibers typed using fluorogenic quantitative PCR are displayed in Figure 2. Expression of the MyHCIIb gene was significantly higher than that of the other 3 muscle fiber genesregardless of growth stage $(\mathrm{P}<0.05)$, which is consistent with the results obtained using the histochemical method.

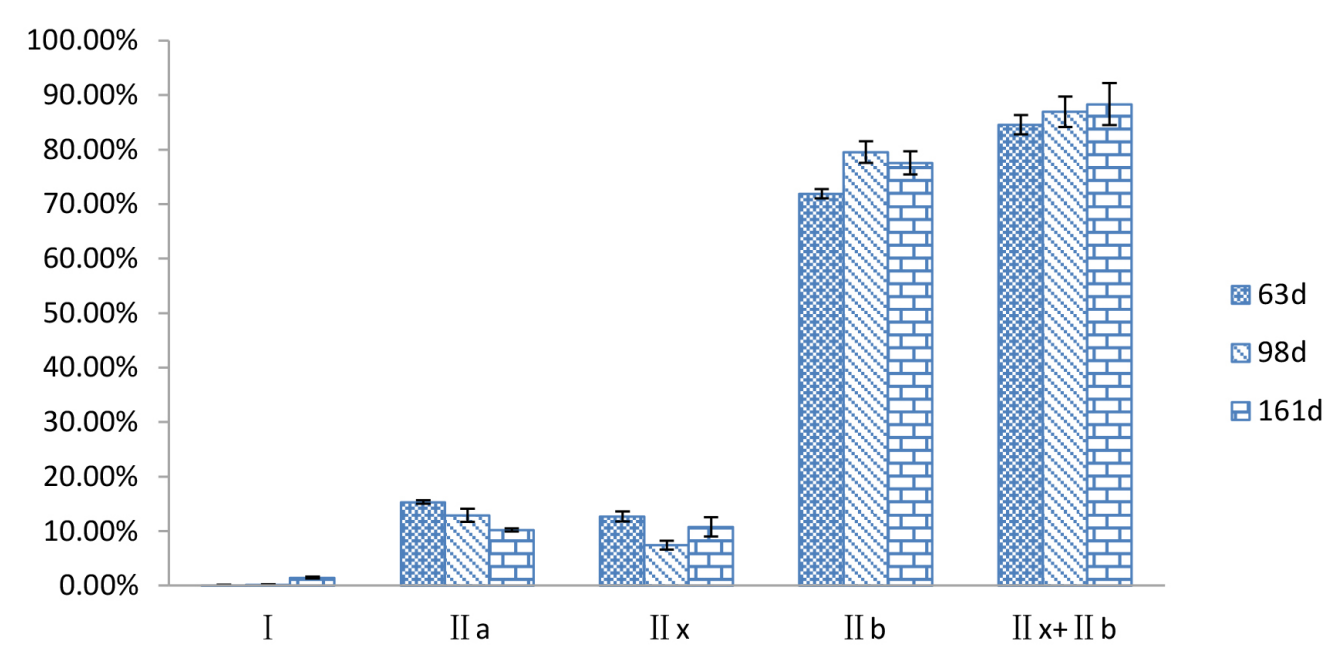

Figure 2. Percentages of MyHC isoforms at 3 growth stages typed using real-time qPDR. The relative amounts of MyHC I, IIa, IIx, AND IIb were expressed as percentage of total MyHC transcripts.

The correlation coefficients between the muscle fiber contents determined by histochemistry and real time qPCR were $0.65,0.88$, and 0.92 for fiber types I, IIa, and IIx+IIb, respectively, which revealed significant positive correlations between the 2 methods.

\section{Meat quality traits at different porcine growth stages}

We measured the meat color and $\mathrm{pH}$ at $45 \mathrm{~min}$ and $24 \mathrm{~h}$ after slaughter and marbling score of the longissimus dorsi muscle at different stages during porcine growth. These results are shown in Table 3. The meat color results are expressed as Commission Internationale de L'Eclairage $\mathrm{L}^{*}\left(\mathrm{a}^{*}\right.$, and $\mathrm{b}^{*} ; \mathrm{a}^{*}$, red index; $\mathrm{b}^{*}$, yellow index; $\mathrm{L}^{*}$, luminosity index). The $\mathrm{L}^{*}$ and $b^{*}$ values were not significantly different at 63,98 , and 161 days. However, the $a^{*}$ value was significantly lower at 98 days $(5.31 \pm 0.68)$ than at 63 days $(12.22 \pm 0.43)$ and 161 days $(9.23 \pm 0.62)$. The $\mathrm{a}^{*}$ value was significantly lowerat 161 days than at 63 days $(\mathrm{P}<0.05)$. The longissimus muscle showed lesser redness at 98 days than at the other 2 stages. The drip loss ratio of meat increased during porcine growth; this ratiowas significantly higher at 161 days $(5.2 \pm 0.4 \%)$ than at 63 and 98 days $(\mathrm{P}<0.05)$.

The meat $\mathrm{pH}$ was measured using a DELTA $320 \mathrm{pH}$ meter at 45 min and $24 \mathrm{~h}$ after slaughter. The $\mathrm{pH}_{24 \mathrm{~h}}$ of the longissimus muscle was significantly higher at 98 days than at 63 and 161 days $(\mathrm{P}<0.05)$. The $\mathrm{pH}$ decrease ratio of meat was significantly lower at 98 days than 
at 161 days $(\mathrm{P}<0.05)$. However, the $\mathrm{pH}$ decrease ratio was not significantly different at 63 days compared with 98 and 161 days $(\mathrm{P}>0.05)$. Marbling scores were assigned using pork quality standards (National Pork Producers Council). The meat marbling score was significantly lower at 63 days $(1.75)$ than at 98 and 161 days $(\mathrm{P}<0.05)$.

Table 3. Meat color (CIE L*, a*, and $\left.\mathrm{b}^{*}\right), \mathrm{pH}_{45 \min }, \mathrm{pH}_{24 \mathrm{~h}}$, and drip loss of the longissimus muscle at different stages during porcine growth.

\begin{tabular}{lccc}
\hline $\mathrm{LM}$ & 63 days & 98 days & 161 days \\
\hline $\mathrm{L}^{*}$ & $40.67 \pm 0.80$ & $40.69 \pm 1.00$ & $40.23 \pm 1.24$ \\
$\mathrm{a}^{*}$ & $12.22 \pm 0.43^{\mathrm{a}}$ & $5.31 \pm 0.68^{\mathrm{c}}$ & $9.23 \pm 0.62^{\mathrm{b}}$ \\
$\mathrm{b}^{*}$ & $8.15 \pm 0.52$ & $8.58 \pm 0.38$ & $7.75 \pm 0.49$ \\
Drip loss & $2.9 \pm 0 . \%^{\mathrm{b}}$ & $3.1 \pm 0.3 \%^{\mathrm{b}}$ & $5.2 \pm 0.4 \%^{\mathrm{a}}$ \\
$\mathrm{pH}_{45 \min }$ & $6.11 \pm 0.04$ & $6.22 \pm 0.08$ & $6.09 \pm 0.08$ \\
$\mathrm{pH}_{24 \mathrm{~h}}$ & $5.48 \pm 0.03^{\mathrm{a}}$ & $5.64 \pm 0.06^{\mathrm{b}}$ & $5.39 \pm 0.03^{\mathrm{a}}$ \\
$\mathrm{pH}^{\mathrm{a}}$ decline ratio & $10.31 \pm 0.42^{\mathrm{ab}}$ & $9.42 \pm 0.70 \%^{\mathrm{a}}$ & $11.56 \pm 0.6 \%^{\mathrm{b}}$ \\
Marbling score & $1.75 \pm 0.07^{\mathrm{a}}$ & $2.35 \pm 0.12^{\mathrm{b}}$ & $2.15 \pm 0.13^{\mathrm{b}}$ \\
\hline
\end{tabular}

Data with different superscripts in the same row are significantly different $(\mathrm{P}<0.05)$. $\mathrm{a}^{*}$, red index; $\mathrm{b}^{*}$, yellow index; $\mathrm{L}^{*}$, luminosity index.

\section{Relationships between muscle fiber composition and meat quality traits}

Table 4 shows the correlation coefficients between muscle fiber contents and meat quality traits. The redness of meat ( $\mathrm{a}^{*}$ value) showed a positive correlation with fiber IIa content $(r=0.72, P<0.01)$ and a negative correlation with fiber IIx + IIb content $(r=-0.69, P$ $<0.01)$. Furthermore, the $\mathrm{a}^{*}$ value showed anegative correlation with the ratio of fiberI/II ( $\mathrm{r}$ $=-0.44, \mathrm{P}<0.05)$. Notably, the content of red fiberI also showed a negative correlation with the $\mathrm{a}^{*}$ value. Drip loss showed a positive correlation with fiber IIx+IIb content $(\mathrm{r}=0.55, \mathrm{P}<$ $0.01)$ and a negative correlation with fiber IIa content $(\mathrm{r}=-0.56, \mathrm{P}<0.01)$. The $\mathrm{pH}$ decrease showed a strong positive correlation with fiber IIx $+\mathrm{IIb}$ content $(\mathrm{r}=0.61, \mathrm{P}<0.01)$ and a negative correlation with fiber IIa content $(\mathrm{r}=-0.44, \mathrm{P}<0.05)$. However, the $\mathrm{pH}$ at $45 \mathrm{~min}$ and 24 $\mathrm{h}$ after slaughter were weakly correlated with muscle fiber contents. Marbling scores showed a positive correlation with fiber I content $(\mathrm{r}=0.52, \mathrm{P}<0.05)$ and the ratio of fiber $\mathrm{I} / \mathrm{II}(\mathrm{r}=0.51$, $\mathrm{P}<0.05)$ and a negative correlation with fiber IIa content $(\mathrm{r}=-0.56, \mathrm{P}<0.05)$.

Table 4. Correlation coefficients $(\mathrm{R})$ between meat quality characteristics and the percentages of different muscle fibers typing by histochemical staining.

\begin{tabular}{lcccccccc}
\hline Muscle fiber type & $\mathrm{L}^{*}$ & $\mathrm{a}^{*}$ & $\mathrm{~b}^{*}$ & Drip loss & $\mathrm{pH}_{45 \min }$ & $\mathrm{pH}_{24 \mathrm{~h}}$ & $\mathrm{pH}$ decline & Marbling score \\
\hline MyHC I & -0.25 & $-0.46^{*}$ & -0.04 & 0.35 & -0.06 & -0.04 & -0.04 & $0.52^{*}$ \\
MyHCIIa & 0.23 & $0.72^{* *}$ & -0.09 & $-0.56^{*}$ & -0.20 & 0.11 & $-0.44^{*}$ & $-0.56^{*}$ \\
MyHCIIx+IIb & -0.15 & $-0.69^{* *}$ & 0.16 & $0.55^{*}$ & 0.30 & -0.12 & $0.61^{* *}$ & 0.41 \\
MyHC I/II & -0.26 & $-0.44^{*}$ & 0.05 & 0.35 & -0.07 & -0.04 & -0.05 & $0.51^{*}$ \\
\hline
\end{tabular}

$* \mathrm{P}<0.05 ; * * \mathrm{P}<0.01 ; \mathrm{a}^{*}$, red index; $\mathrm{b}^{*}$, yellow index; $\mathrm{L}^{*}$, luminosity index; $\mathrm{N}=18$.

\section{DISCUSSION}

Fast-growing pigs showed a higher percentage of glycolytic fibers. These results were consistent with those of previous studies (Larzul et al., 1997; Zhang et al., 2013). In the grow- 
ing period, the percentage of oxidative red fibers (I and IIa) was decreased and the percentage of glycolytic white fibers (IIx+IIb) was increased. These observations suggest that the glycolytic capacity of the longissimus dorsi muscle and maximum contraction speed increase over the 63-161 day period, whereas oxidation capacity decreases (Lefaucheur et al., 2002).

The histochemical method for classifying muscle fibers is based on the physicochemical characteristics of muscle fibers. It is well reflected the metabolism difference and contraction difference of muscle fibers. But this method is prone to error because of the high workload and subjectivity of measurements (Klont et al., 1998). The qPCR method for classifying muscle fibers is on the transcriptional level, unable representing the expression of myosin protein. So it is an indirect method. Therefore, we also used qPCR to type muscle fibers and determine the correlation between the 2 methods. The MyHC I, IIa, and IIx+IIb contents determined using histochemistry and qPCR showed similar trends at the 3 growth stages. However, some differences were observed using the 2 methods. The percentage of fiber IIx+IIb was significantly higher when typed using qPCR (approximately 85\%) compared with the traditional method (approximately 80\%), whereas the proportion of fiber I was lower. These results suggested that muscle fiber composition does not significantly change during the pig fatting stage, but the level of fiber IIb composition increases. Previous studies have shown that the conversion of muscle fiber types predominantly occurs during the embryonic period and within 2 weeks after birth.

The result of meat quality traits at different stages revealed that the redness of longissimus muscle was decreased during porcine growth. The drip loss ratio, the $\mathrm{pH}$ decrease ratio and the marbling score of meat increased during porcine growth. It may be caused by the changes of muscle fiber contents. Ryu and Kim (2006) used the $\mathrm{L}^{*}$ value and drip loss ratio to determine meat quality and classified the meat as pale, soft, and exudative meat (PSE, L* $\leq$ 50 , drip loss $>6 \%$ ); dark, firm, and dry meat (DFD, $\mathrm{L}^{*}<43$, drip loss $<2 \%$ ), or reddish pink, firm, and non exudative (RFN, L* $\leq 50$, drip loss $<6 \%$ ) (Pette and Staron, 2000). Based on this classification, all samples in our study represented healthy meat.

The results of correlation analysis between muscle fiber contents and meat color revealed that the redness of meat showed a positive correlation with red fiber contents and a negative correlation with white fiber contents. So increasing red fiber content should cause increased redness. However, meat color is a complex trait affected by many factors, including genotype, nutrition, and pre-slaughter handling (Pette and Staron, 2001). Water-holding capacity and marbling are important meat quality traits. The MyHC isoform content may affect these traits (Jordan et al., 2005). The results in our study suggest that the water-holding capacity of red fibers is better than that of white fibers. These results are not consistent with those of a previous study (Bach et al., 2004). The results of correlation analysis between muscle fiber contents and meat $\mathrm{pH}$ suggest that muscle fiber composition does not significantly influence postmortem meat $\mathrm{pH}$. However, the fiber IIb content affected the rate of decrease of meat $\mathrm{pH}$. High glycolytic capacity causes rapid postmortem glycolysis and lactic acid accumulation and induces a rapid decrease in muscle $\mathrm{pH}$ (Bach et al., 2004). The glycolytic capacity of postmortem muscle is determined based on muscle fiber composition (Russell et al., 2003). Therefore, muscle fiber composition affects the rate of decrease of postmortem muscle $\mathrm{pH}$. Increased fat deposition during later stages of porcine growth affected the muscle marbling score. A previous study showed that the muscle fiber type was not correlated with intramuscular fat and muscle marbling; however, other studies showed different results. Therefore, the relationship between muscle fiber composition and muscle marbling remains unclear. Our results suggest that muscle fiber composition regulates muscle marbling. 


\title{
Conflicts of interest
}

The authors declare no conflict of interest.

\section{ACKNOWLEDGMENTS}

\author{
Research supported by the National Basic Research Program (“973” project), Project \\ \#2012CB12470.
}

\section{REFERENCES}

Bach LH, Raney NE, Doumit ME, Helman EE, et al. (2004). Differential gene expression in proliferating and differentiating porcine skeletal muscle satellite cells. J. Anim. Sci. 82: 107.

Baker DM and Santer RM (1990). Development of a quantitative histochemical method for determination of succinate dehydrogenase activity in autonomic neurons and its application to the study of aging in the autonomic nervous system. J. Histochem. Cytochem. 38: 525-531.

Brooke MH and Kaiser KK (1970). Muscle fiber types: how many and what kind? Arch. Neurol. 23: 369-379.

Bustin SA, Benes V, Garson JA, Hellemans J, et al. (2009). The MIQE guidelines: minimum information for publication of quantitative real-time PCR experiments. Clin. Chem. 55: 611-622.

Jiang H, Jordan T, Li J, Li H, et al. (2004). Innervation-dependent and fiber type-specific transcriptional regulation of the slow myosin heavy chain 2 promoter in avian skeletal muscle fibers. Dev. Dyn. 231: 292-302.

Joo ST, Kim GD, Hwang YH and Ryu YC (2013). Control of fresh meat quality through manipulation of muscle fiber characteristics. Meat Sci. 95: 828-836.

Jordan T, Jiang HB, Li H and DiMario JX (2005). Regulation of skeletal muscle fiber type and slow myosin heavy chain 2 gene expression by inositol trisphosphate receptor 1. J. Cell Sci. 118: 2295-2302.

Karlsson AH, Klont RE and Fernandez X (2000). Skeletal muscle fibres as factors for pork quality. In: Quality of meat and fat in pigs as affected by genetics and nutrition. Wageningen Academic Publishers, Wageningen, 47-67.

Klont RE, Brocks L and Eikelenboom G (1998). Muscle fibre type and meat quality. Meat Sci. 49: S219-S29.

Larzul C, Lefaucheur L, Ecolan P, Gogué J, et al. (1997). Phenotypic and genetic parameters for longissimus muscle fiber characteristics in relation to growth, carcass, and meat quality traits in large white pigs. J. Anim. Sci. 75: 3126-3137.

Lee SH, Joo ST and Ryu YC (2010). Skeletal muscle fiber type and myofibrillar proteins in relation to meat quality. Meat Sci. 86: 166-170.

Lefaucheur L, Ecolan P, Plantard L and Gueguen N (2002). New insights into muscle fiber types in the pig. J. Histochem. Cytochem. 50: 719-730.

Lefaucheur L, Milan D, Ecolan P and Le Callennec C (2004). Myosin heavy chain composition of different skeletal muscles in Large White and Meishan pigs. J. Anim. Sci. 82: 1931-1941.

Lin J, Wu H, Tarr PT, Zhang CY, et al. (2002). Transcriptional co-activator PGC-1 alpha drives the formation of slowtwitch muscle fibres. Nature 418: 797-801.

Nachlas MM, Tsou KC, De Souza E, Cheng CS, et al. (1957). Cytochemical demonstration of succinic dehydrogenase by the use of a new p-nitrophenyl substituted ditetrazole. J. Histochem. Cytochem. 5: 420-436.

Norman JL, Berg EP, Ellersieck MR and Lorenzen CL (2004). Prediction of color and pH measurement throughout boneless center-cut pork loins. Meat Sci. 66: 273-278.

Pette D and Staron RS (2000). Myosin isoforms, muscle fiber types, and transitions. Microsc. Res. Tech. 50: 500-509.

Pette D and Staron RS (2001). Transitions of muscle fiber phenotypic profiles. Histochem. Cell Biol. 115: 359-372.

Plomgaard P, Penkowa M, Leick L, Pedersen BK, et al. (2006). The mRNA expression profile of metabolic genes relative to MHC isoform pattern in human skeletal muscles. J. Appl. Physiol. 101: 817-825.

Russell AP, Feilchenfeldt J, Schreiber S, Praz M, et al. (2003). Endurance training in humans leads to fiber type-specific increases in levels of peroxisome proliferator-activated receptor- $\gamma$ coactivator- 1 and peroxisome proliferatoractivated receptor- $\alpha$ in skeletal muscle. Diabetes 52: 2874-2881.

Ryu YC and Kim B C (2006). Comparison of histochemical characteristics in various pork groups categorized by postmortem metabolic rate and pork quality. J. Anim. Sci. 84: 894-901.

Schäfer A, Rosenvold K, Purslow PP, Andersen HJ, et al. (2002). Physiological and structural events post mortem of importance for drip loss in pork. Meat Sci. 61: 355-366.

Schiaffino S and Reggiani C (1994). Myosin isoforms in mammalian skeletal muscle. J. Appl. Physiol. 77: 493-501.

Genetics and Molecular Research 14 (3): 7873-7882 (2015) CFUNPEC-RP www.funpecrp.com.br 
Scott W, Stevens J and Binder-Macleod SA (2001). Human skeletal muscle fiber type classifications. Phys. Ther. 81: 1810-1816.

Takawa M, Cho HS, Hayami S, Toyokawa G, et al. (2012). Histone lysine methyltransferase SETD8 promotes carcinogenesis by deregulating PCNA expression. Cancer Res. 72: 3217-3227.

Wimmers K, Ngu NT, Jennen DG, Tesfaye D, et al. (2008). Relationship between myosin heavy chain isoform expression and muscling in several diverse pig breeds. J. Anim. Sci. 86: 795-803.

Yang YL, Li Y, Liang RY, Zhou R, et al. (2014). Dynamic expression of microRNA-127 during porcine prenatal and postnatal skeletal muscle development. J. Integr. Agr. 13: 1331-1339.

Ye RS, Xi QY, Qi Q, Cheng X, et al. (2013). Differentially expressed miRNAs after GnRH treatment and their potential roles in FSH regulation in porcine anterior pituitary cell. PLoS One 8: e57156.

Zhang SH, Zhu L, Wu ZH, Zhang Y, et al. (2013). Effect of muscle-fiber type on glycogenin-1 gene expression and its relationship with the glycolytic potential and pH of pork. Genet. Mol. Res. 12: 3383-3390. 